\title{
KUCA: Kocaeli University Converter Analysis simulation software in power electronics
}

\author{
Farzin Asadi ${ }^{1, *}$, Nurettin Abut ${ }^{2}$ \\ ${ }^{1}$ Engineering Department, Faculty of Mechatronics Engineering, Kocaeli University, Kocaeli, Turkey \\ ${ }^{2}$ Engineering Department, Faculty of Electrical Engineering, Kocaeli University, Kocaeli, Turkey
}

\section{A R T I C L E IN F O}

\section{Article history:}

Received 2 September 2016

Received in revised form

22 November 2016

Accepted 30 November 2016

\section{Keywords:}

Circuit analysis

Circuit simulation

Education

Power electronics

Graphical user interface

\begin{abstract}
A B S T R A C T
This paper describes how a circuit simulation program can assist in teaching the principles of power electronics to undergraduate students. The authors have used Kocaeli University Converter Analysis suite (KUCA) as an aid to teaching principles of power electronics to undergraduate students in either Iran or Turkey. Using KUCA has increased students ability to comprehend the analysis of main building block of power electronics converter circuits. KUCA comes with a user friendly Graphical User Interface (GUI). Drawing the schematic from scratch is not required at all. Selecting the desired topology from a list is all what needs. KUCA can analyses almost all the topologies required for an undergraduate level power electronics course. Transient response, steady state response and harmonic content of desired signal can be obtained quickly and easily which may be very cumbersome, time consuming and error prone to do with pencil-and-paper analysis.
\end{abstract}

(C) 2016 The Authors. Published by IASE. This is an open access article under the CC BY-NC-ND license (http://creativecommons.org/licenses/by-nc-nd/4.0/)

\section{Introduction}

Matching the voltage and current requirement of the load to the input source is an overall objective of a power electronics converter.

Some of the benefit of simulation in the process of analysis and design of power converters are listed below (Hart, 1993; Chamas and Nokali, 2004):

1. Observing current and voltage waveform give insight into the circuit. Obtaining waveform is not always possible with the pencil-and-paper analysis. Nonlinear nature of power electronic switches and parasitic elements, i.e. capacitor or inductor equivalent series resistance, make the analysis cumbersome.

2. Circuit simulation can be used as a design tool for proper circuit elements selection. For example, current, voltage and dissipated power of semiconductor switches must be confined to a certain range provided by the producer. Working outside of this Safe Operating Area (SOA) lead to device corruption.

\footnotetext{
* Corresponding Author.

Email Address: farzin.asadi@kocaeli.edu.tr (F. Asadi) https://doi.org/10.21833/ijaas.2016.12.008

2313-626X/C 2016 The Authors. Published by IASE.

This is an open access article under the CC BY-NC-ND license

(http://creativecommons.org/licenses/by-nc-nd/4.0/)
}

3. Using a simulation program, investigation of circuits current and voltages is usually more efficient, easier and safer, than in a hardware laboratory.

4. Circuit simulation is a cheap way to discover possible problems of the circuit before realization.

Therefore circuit simulation is an important tool for power converter circuit design and analysis. There are many simulation software available for this purpose. Some of the most famous packages are:

\subsection{PSpice ${ }^{\circledR}$}

PSpice is one of the well-known circuit simulation programs. It is able to do either analogue or digital simulations. Plenty of textbooks provide Pspice based examples and exercises so students generally have some idea about Pspice simulations. Student evaluation version of Pspice is made available freely although there are some restrictions on the maximum number of nodes/components.

\subsection{NI Multisim $®$}

NI Multisim is a powerful schematic capture and simulation program. NI Multisim has an easy and user friendly interface, as well as plenty of ready to use parts.NI Multisim is widely used in academia and industry. 


\subsection{PSIM $®$}

Although PSIM can be used to simulate any electronics circuit, it is designed specifically for use in power electronics and motor drive simulations. PSIM has various add on modules which extends its functionality to specific areas of circuit simulation and design. PSIM simulations run much faster than SPICE based circuit simulation programs. PSIM has a free demo version.

\subsection{SABER®}

SABER is a nonlinear dynamic system simulation program. Power electronics converters are nonlinear dynamic systems in general. So SABER can be used to simulate them. SABER users can define new models in FORTRAN, $\mathrm{C}$ or in a dedicated description language (MAST). SABER is compatible with PSPICE. Student evaluation of SABER is not available.

\subsection{Matlab® and Simulink TM}

Simulink and Simscape power system toolbox of Matlab provide an environment to analyze power electronics circuits by drawing the schematic.

All of the aforementioned software needs a considerable amount of time to learn as well as to use the software.

KUCA is optimized for class room use. KUCA can help instructors in the following ways:

1- When an example is solved by hand, correctness of obtained results can be verified using KUCA. Effect of circuit non-idealities can be studies with KUCA. Pencil-and-Paper analysis in presence of these non-idealities is quite lengthy and cumbersome. There is no need to drawing circuit, so instructor can answer students question quickly by pressing just a button.

2- Power converters circuit design can be thought with the aid of KUCA. For proper functioning of a power electronics converter, designer must consider following quantities for each component:

i. Maximum and average dissipated power in the component,

ii. Maximum and average current through the component,

iii. Maximum and average voltage across the component.

KUCA gives all the above mentioned quantities for each component of circuit. Given the above quantities and data sheet of selected part, students can decide whether selected part can work in the circuit safely or not. So students learn to think like an engineer.

3- Effect of change in parameters can be studied easily with multigraph property of KUCA. Drawing different simulations results on the same graph make the comparison possible.
4- Students' main goal is to understand the teaching content. Thus, the introduction of a sophisticated simulation tool may lead to additional challenges. Working with KUCA is simple enough. Its documentation and video tutorial make the work even easier.

\section{Related Works}

Importance of computer simulation in teaching undergraduate power electronics course is studied in Hart (1993). iPES is introduced by Power Electronic Systems Laboratory as an online education platform in 2001 (Drofenik et al., 2001; Online: www.ipes.ethz.ch). Circuit simulator GeckoCIRCUITS was developed and used as an extension of iPES platform (Drofenik et al., 2010). Since 2013, GeckoCIRCUITS is available as free opensource software (Online: www.geckosimulations.com/geckocircuits.html). New features are added to GeckoCIRCUITS in Müsing and Kolar (2014). Matlab ${ }^{\circledR}$ and Simulink ${ }^{\mathrm{TM}}$ interfaced with a GUI in Visual C++ to implement a simulation package in Path and Chandrasekaran (1997). Educational use of free circuit simulation package named SEQUEL is studied in Raju and Karnik (2009). A toolbox for power electronic circuit's simulation is developed based on VisSim ${ }^{\mathrm{TM}}$ in Ustun et al. (2000). Using computers for circuit simulation has been studied in (Director, 1975; Kundert, 1995).

\section{KUCA's organization}

Fig. 1 shows main menu of KUCA. User can select the topology which he wants.

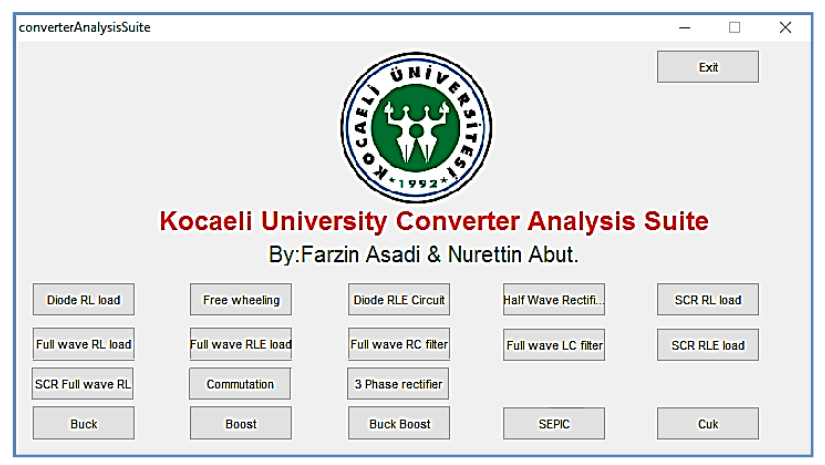

Fig. 1: Main menu of KUCA

Some of the analysis that version 1 of KUCA can do are as follows.

\subsection{Diode with R-L load}

Figs. 2-3 show diode with R-L load analysis section of the software. Students generally have no difficulty in understanding diode with a pure resistive load circuit analysis. In Diode-L-R circuit's diode does not become reverse bias as soon as input source voltage becomes negative because of inductance. 
Students, especially in a first course of power electronics, have difficulty in understanding this concept.

Using this section of software, this concept can be understood easily with the aid of current and voltage waveform of diode. Effect of increasing or decreasing the time constant of R-L load on the output voltage and load current can be studied very easily. Waveforms obtained from different analysis (with different values of parameters) can be drawn on the same graph so effect of change can be seen clearly.

Using this section of software following waveform can be shown:

1. Diode instantaneous and average current waveform,

2. Diode instantaneous and average voltage waveform,

3. Diode instantaneous and average power waveform,

4. Resistor and inductor voltage waveform,

5. R-L load voltage waveform,

6. Dissipated power in R-L load (Resistor power),

7. Inductor instantaneous power waveform.

Simulation time can be set by the user. Transient and steady state response are shown. User can zoom in or out on the desired wave form to have a better view.

Waveform can be saved in desired graphic format like .bmp or .jpg when needed.

Using this section of software selection of semiconductor device (In this topology a diode) is a simple and straight forward task. Maximum and average value of the voltage, current and dissipated power in the semiconductor device is drawn by KUCA. Using this data designer can decide whether device can withstand or not.

When this configuration is used to transfer energy from an AC source to a DC motor or when this set up is used to charge a battery, motor EMF or battery potential must be taken into account. As shown in Fig. 4, R-L-Source loads can be analyzed too.

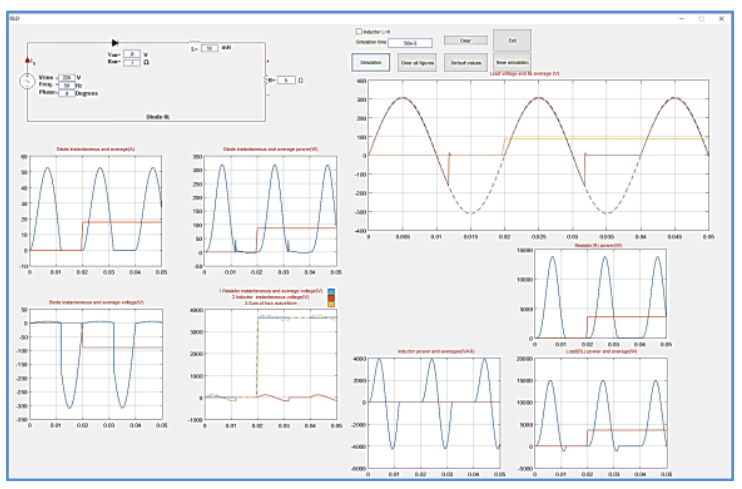

Fig. 2: Diode with R-L source

Effect of inductor on transferred energy can be observed with changing the value of inductor (Fig. 5).

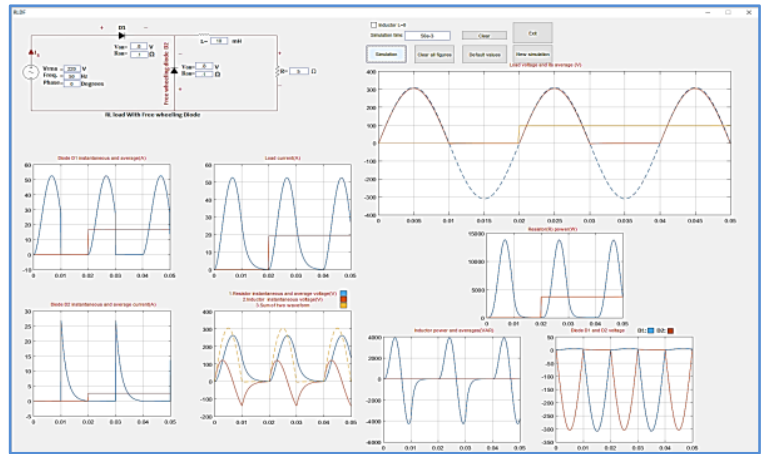

Fig. 3: Adding freewheeling diode to R-L load

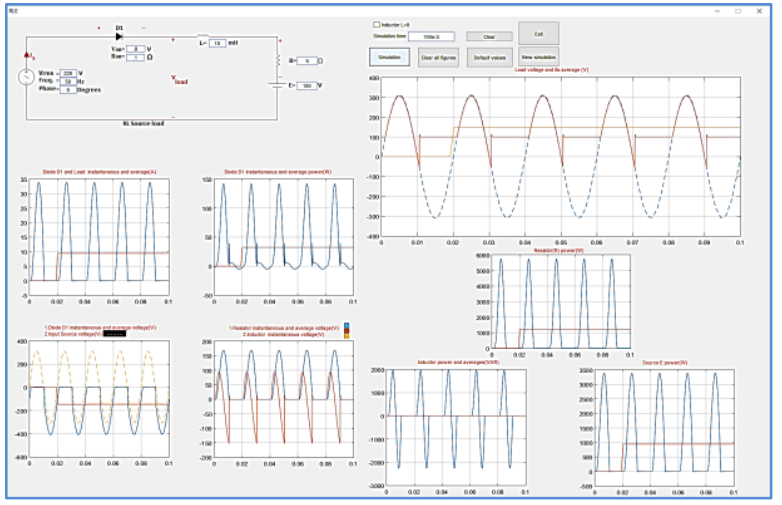

Fig. 4: Diode with R-L-Source load

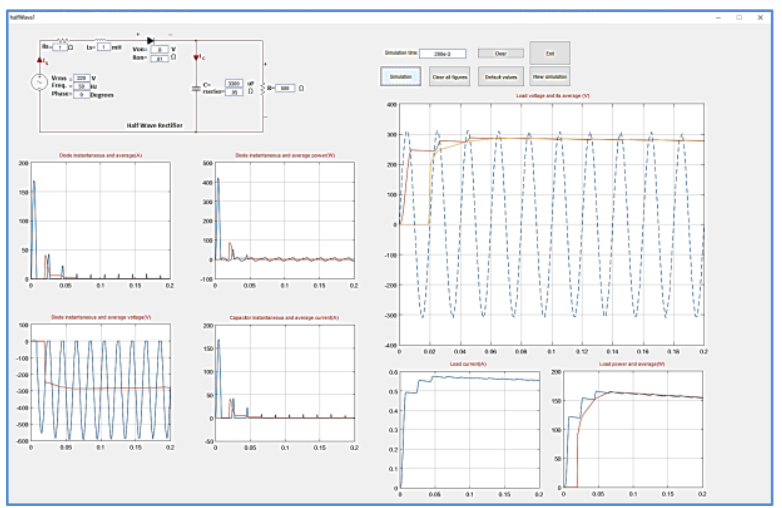

Fig. 5: Adding capacitor to decrease load voltage ripples.

\subsection{Commutation process of Switches}

When input AC source has inductive output impedance, e.g. secondary of a transformer, there is a commutation process between diodes D1 and D2 of topology shown in Fig. 6. In some instant of time diodes D1 and D2 become on simultaneously. Calculation of commutation angle can be found in any standard text book of power electronic. KUCA draws current waveform of diodes D1 and D2 on the same graph. So concept of commutation can be understood easily and quickly.

Effect of input source inductance and load inductance on the commutation angle can be studied easily using this section.

\subsection{Controlled rectifier}

When a variable output voltage (in terms of average or RMS value) is needed, controlled rectifier must be used. As shown in Figs. 7-8, firing angle of 
SCR can be set by user. Like previous parts of the software, current, voltage and power waveforms can be drawn. Given SCR current, voltage and power waveform is a great help to select the proper device for a design problem.

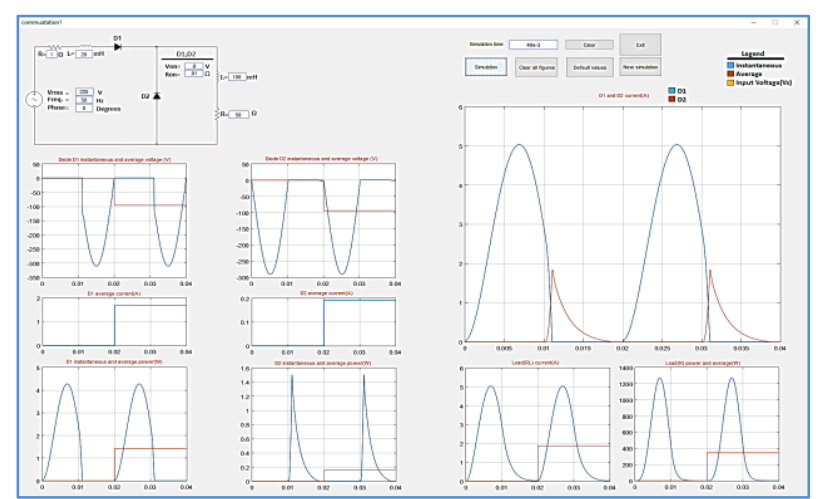

Fig. 6: Commutation process

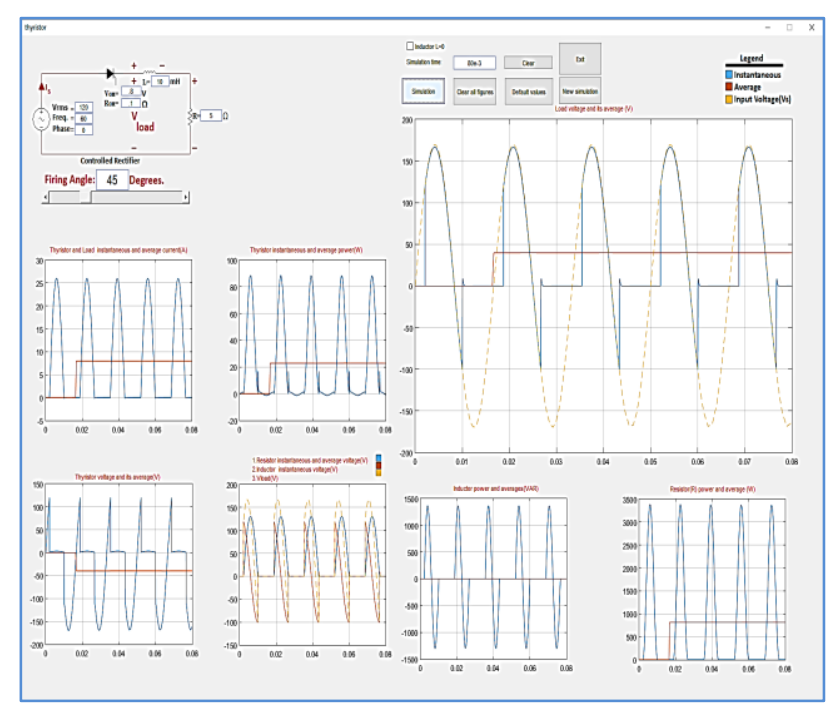

Fig. 7: SCR with R-L load

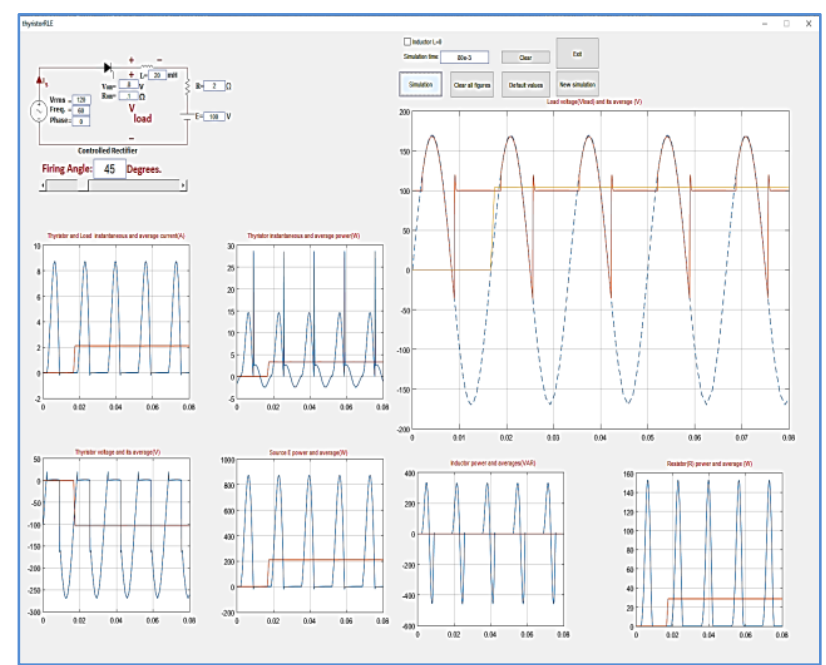

Fig. 8: SCR with R-L-Source load

\subsection{Full wave rectifier}

Half wave rectifiers use either the positive or negative half of the input waveform while the other half is blocked. When a greater output voltage (In terms of average value or RMS) is needed full wave rectifier must be used. KUCA can analyze full wave controlled and uncontrolled rectifier circuits as shown in Figs. 9-13. This section of software gives circuit's current, voltage and power waveforms like other sections. Load can be either R-L or R-L-source.

When low level of output ripple is needed a capacitor must be connected in parallel with the load. Low ripple is obtained with a large capacitor. Although large capacitor decreases ripple content, it increases surge current of diodes. Effect of capacitance on the current waveform can be observed quickly with the aid of KUCA.

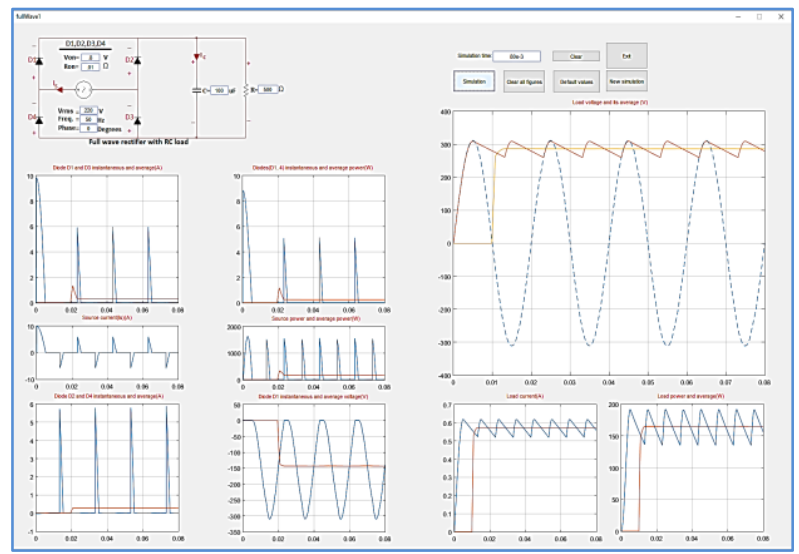

Fig. 9: Uncontrolled Full wave rectifier with capacitor filter

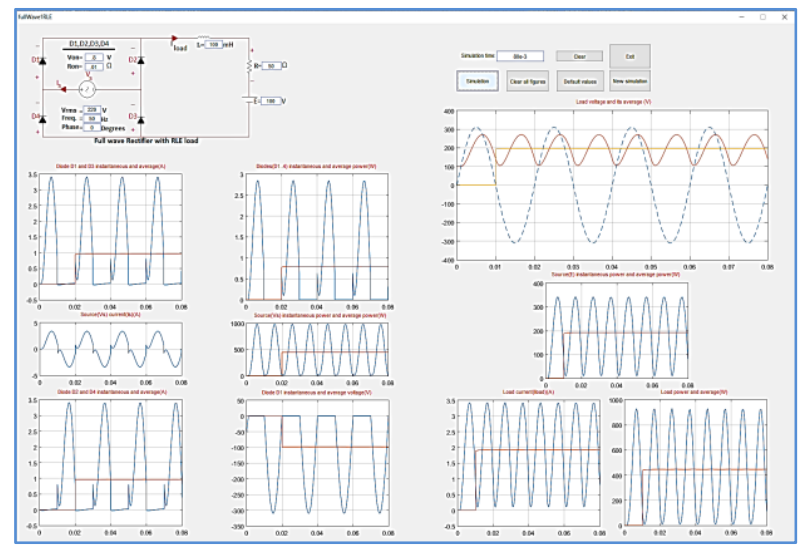

Fig. 10: Uncontrolled full wave with R-L-source load

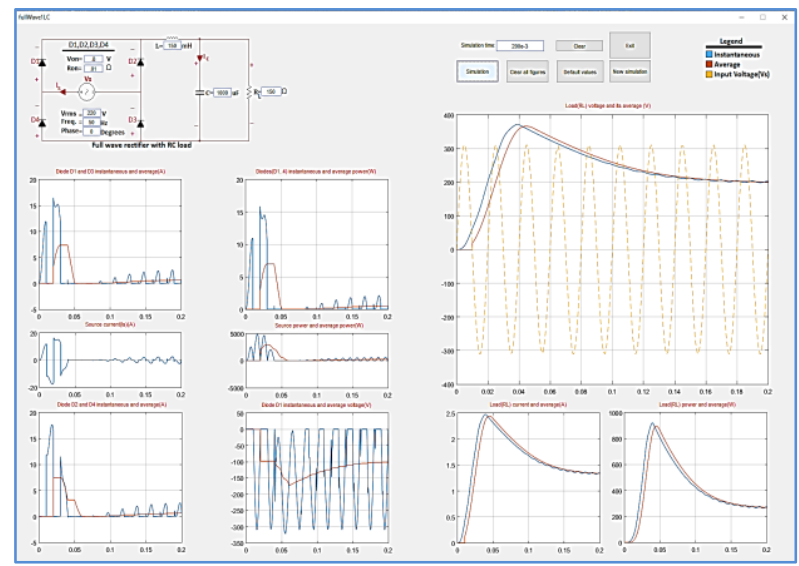

Fig. 11: Uncontrolled full wave rectifier with L-C filter 


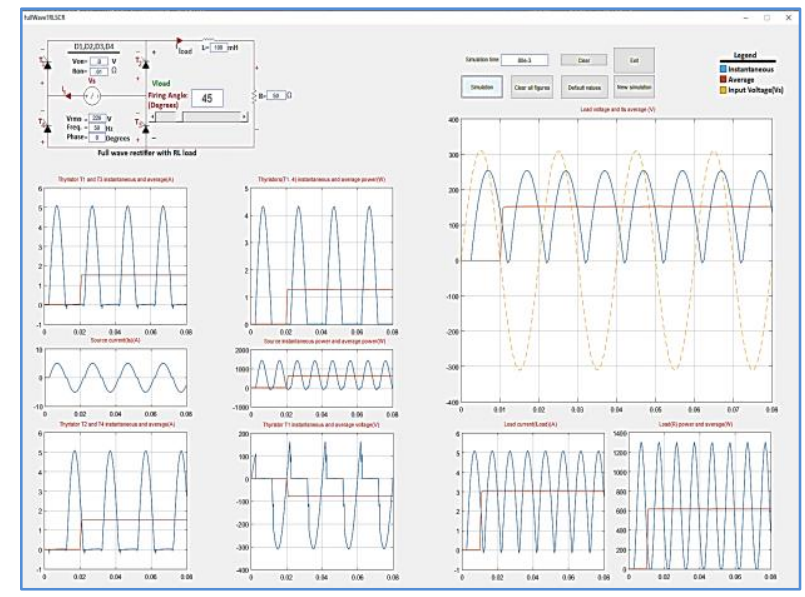

Fig. 12: Controlled full wave rectifier with R-L load

\subsection{Phase Rectifier}

3 phase circuits can be analyzed too. 3 phase source impedance can be included if necessary. Load can be R, R-L or R-L-Source.

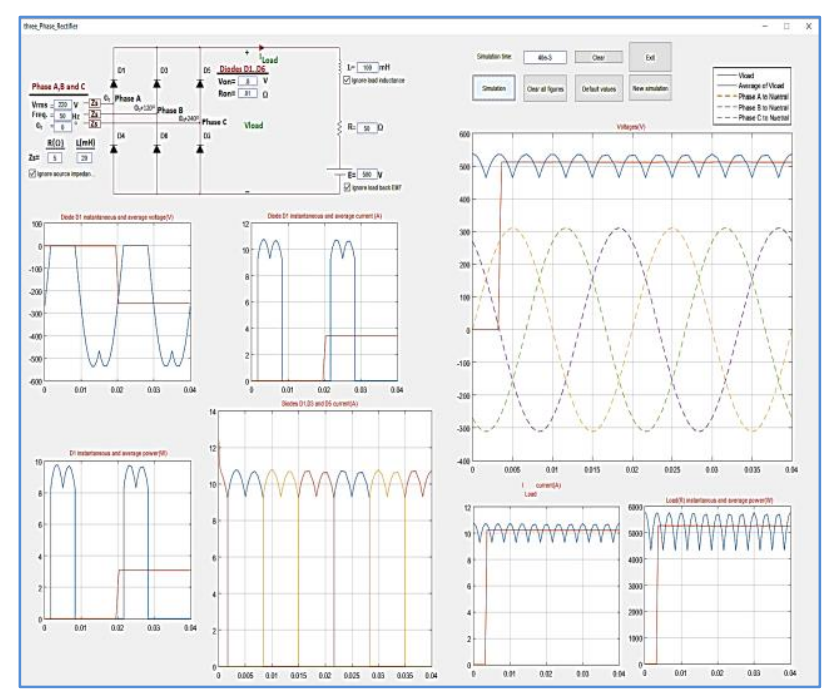

Fig. 13: 3 phase rectifier with R-L-Source load and input source impedance. R, R-L or loads can be analyzed too

\subsection{DC-DC converter}

DC-DC converters are important building blocks of power electronic courses. Buck, Boost, BuckBoost, SEPIC and Cuk can be analyzed with the aid of version 1 of KUCA (Figs. 14-18). All the circuit waveforms are calculated in presence of circuit's non idealities like: Inductor and capacitor's series resistance, diode's series resistance and voltage drop, mosfet's on resistance and input source's internal resistance.

PWM frequency and duty ratio can be set by the user. Efficiency of converter in presence of above non idealities can be drawn.

Working mode of converter (DCM or CCM) can be understood easily by looking at inductor current waveform.

Based on waveforms given by software, semiconductor switches can be chosen easily to withstand working condition the circuit.

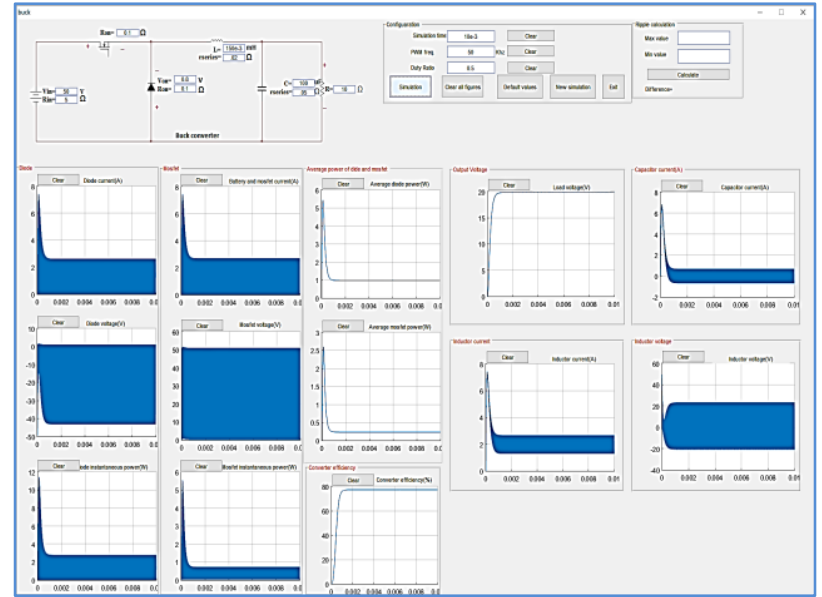

Fig. 14: Buck converter circuit

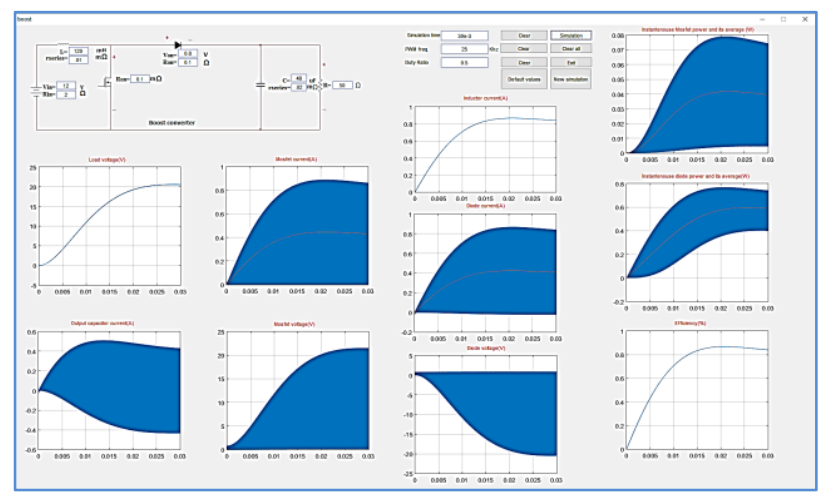

Fig. 15: Boost converter circuit

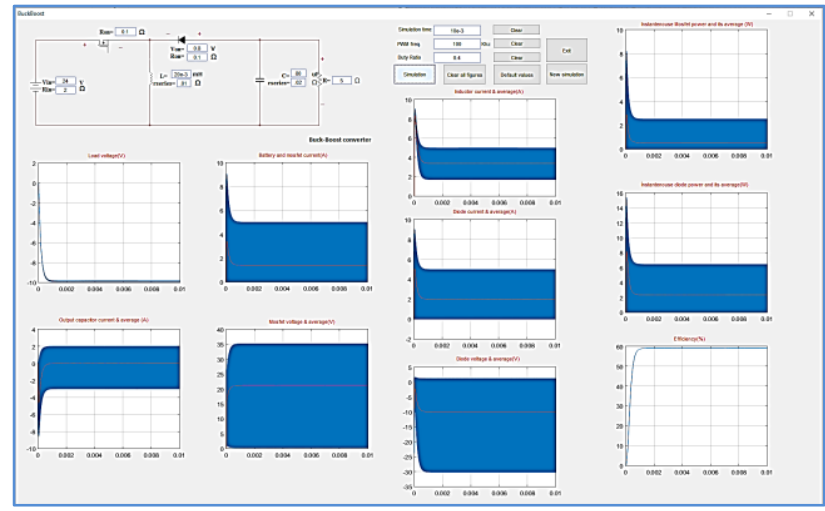

Fig. 16: Buck-Boost converter circuit

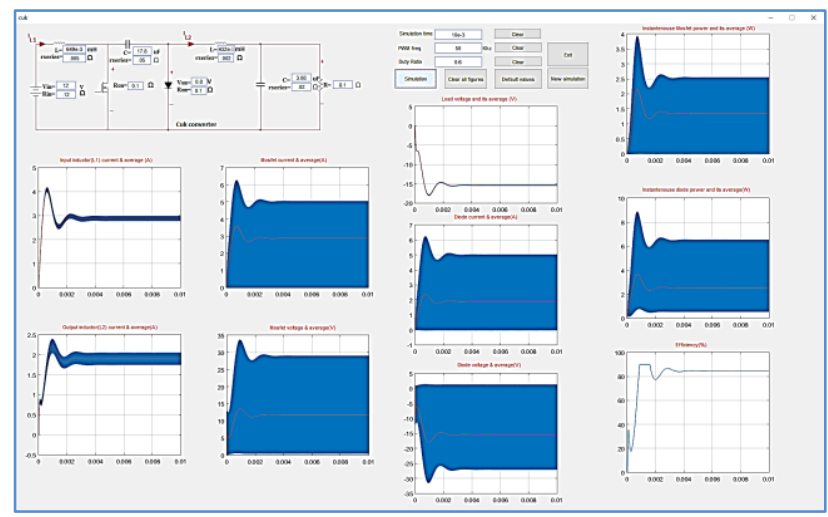

Fig. 17: Cuk converter circuit

\section{Conclusion}

Large amount of information must be covered during a semester in a power electronics course. 
Time shortage cause many questions in the classroom to receive insufficient attention.

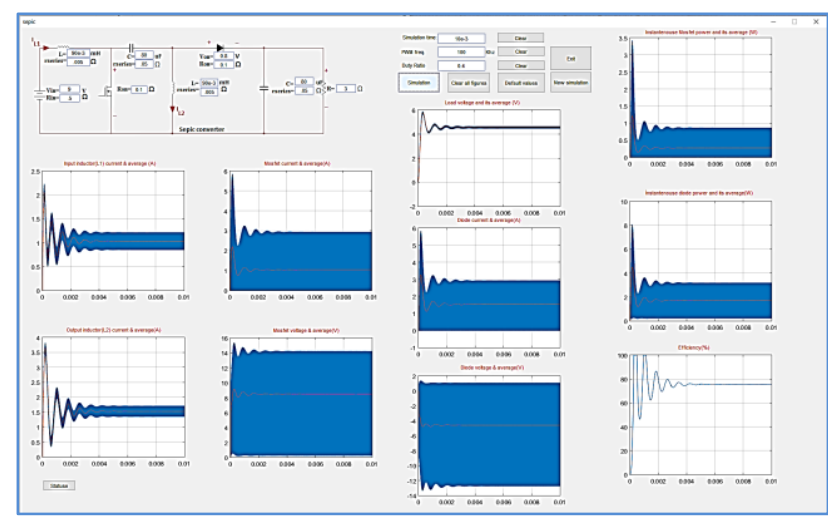

Fig. 18: SEPIC converter circuit

A circuit simulation program is developed here. Designed software has an easy to use GUI and almost all the topologies covered in an undergraduate level power electronics course. There is no need to draw the circuit schematic. User selects the desired topology from a list and set the parameters to desired values.

Different simulation results (with different values of parameters) can be drawn on the same graph which makes comparison possible. Students can see the effects of non-idealities on circuit operation quickly. Considering effects of these non-idealities are quite cumbersome with pencil-and-paper analysis.

Designed software has been used as an aid for teaching power electronics course both in Iran and Turkey. Authors received a positive response from students, having enhanced their understanding of theoretical concepts covered in the course.

\section{References}

Chamas I and Nokali MAE (2004). Automated PSpice simulation as an effective design tool in teaching power electronics. IEEE Transactions on Education, 47(3): 415-421.

Chua LO and Lin PY (1975). Computer-aided analysis of electronic circuits: algorithms and computational techniques. Prentice Hall Professional Technical Reference, Englewood Cliffs, USA.

Director SW (1982). Computer-aided circuit design: Simulation and optimization. John Wiley \& Sons, Inc. New York, USA.

Drofenik U and Kolar JW (2002). Interactive Power Electronics Seminar (iPES)-a web-based introductory power electronics course employing Java-applets. In the IEEE $33^{\text {rd }}$ Annual Power Electronics Specialists Conference (PESC '02): 443-448. https://doi.org/10.1109/PSEC.2002.10 22493

Drofenik U and Kolar JW (2002). Survey of modern approaches of education in power electronics. In the $17^{\text {th }}$ Annual IEEE Applied Power Electronics Conference and Exposition (APEC '02): 749-755. https://doi.org/10.1109/APEC.2002.989329

Drofenik U, Kolar JW, van Duijsen PJ and Bauer P (2001). New web-based interactive e-learning in power electronics and electrical machines. In the Conference Record of IEEE Industry Applications Conference. Thirty-Sixth IAS Annual Meeting: 1858-1865. https://doi.org/10.1109/IAS.2001.9 55784

Drofenik U, Müsing A and Kolar JW (2010). Novel online simulator for education of power electronics and electrical engineering. In IEEE International Power Electronics Conference (IPEC '10): 1105-1111. https://doi.org/10.1109/IPEC. 2010.5543198

Hart DW (1993). Circuit simulation as an aid in teaching the principles of power electronics. IEEE Transactions on Education, 36(1): 10-16.

Jensen RW and MacNamee LP (1976). Handbook of circuit analysis languages and techniques. Englewood Cliffs, Prentice-Hall, New Jersey, USA.

Kundert KS (1995). The designer's guide to spice and spectre. Kluwer, Norwell, USA.

McCalla WJ (2012). Fundamentals of computer-aided circuit simulation. Kluwer, Norwell, USA.

Mohan N, Robbins WP, Undeland TM, Nilssen R and Mo $O$ (1994). Simulation of power electronic and motion control systems-an overview. Proceedings of the IEEE, 82(8): 1287-1302. https://doi.org/10.1109/5.301689

Müsing A and Kolar JW (2014). Successful online education-GeckoCIRCUITS as open-source simulation platform. In IEEE International Power Electronics Conference (IPEC-Hiroshima 2014ECCE ASIA): 821-828. https://doi.org/10.1109/ IPEC.2014.6869683

Path D and Chandrasekaran A (1997). A novel approach to the design and implementation of a power electronics simulation software package. In the IEEE Proceedings of the Twenty-Ninth Southeastern Symposium on System Theory: 473476. https://doi.org/10.1109/SSST.1997.581711

Patil MB, Das SP, Joshi A and Chandorkar M (2002). A new public-domain simulator for power electronic circuits. IEEE Transactions on Education, 45(1): 79-85.

Pederson D (1984). A historical review of circuit simulation. IEEE Transactions on Circuits and Systems, 31(1): 103-111.

Raghuram R (1989). Computer simulation of electronic circuits. Wiley, New York, USA.

Raju AB and Karnik SR (2009). SEQUEL: A free circuit simulation software as an aid in teaching the principles of power electronics to undergraduate students. In the IEEE 2nd 
International Conference on Emerging Trends in Engineering and Technology (ICETET '09): 681686. https://doi.org/10.1109/ICETET.2009.200

Rashid MH (2003). SPICE for circuits and electronics using PSPICE schematics. 2nd ed., Prentice-Hall, Englewood Cliffs, New Jersey, USA.

Rashid MH (2005). Power Electronics: Circuits, devices and applications. $3^{\text {rd }}$ Edition, PHI Publication, New-Delhi, India.
Schwartz AP (1987). Computer aided design of microelectronic circuit and system. Academic, London, UK.

Ustun O, Yilmaz M and Tuncay RN (2000). Simulation of power electronic circuits using VisSim TM software: a study on toolbox development. In the 7th IEEE Workshop on Computers in Power Electronics (COMPEL): 183187. https://doi.org/10.1109/CIPE.2000.904713

Vlach J and Singhal K (1983). Computer methods for circuit analysis and design. Van Nostrand Reinhold, New York, USA. 